\title{
Lead-free double halide perovskite Cs3BiBr6 with well-defined crystal structure and high thermal stability for optoelectronics
}

Tang, Yingying; Liang, Mingli; Chang, Bingdong; Sun, Hongyu; Zheng, Kaibo; Pullerits, Tönu; Chi, Qijin

Published in:

Journal of Materials Chemistry C

Link to article, DOI:

10.1039/C8TC05480K

Publication date:

2019

Document Version

Peer reviewed version

Link back to DTU Orbit

Citation (APA):

Tang, Y., Liang, M., Chang, B., Sun, H., Zheng, K., Pullerits, T., \& Chi, Q. (2019). Lead-free double halide perovskite $\mathrm{Cs}_{3} \mathrm{BiBr}$ with well-defined crystal structure and high thermal stability for optoelectronics. Journal of Materials Chemistry C, 7(11), 3369-3374. https://doi.org/10.1039/C8TC05480K

\section{General rights}

Copyright and moral rights for the publications made accessible in the public portal are retained by the authors and/or other copyright owners and it is a condition of accessing publications that users recognise and abide by the legal requirements associated with these rights.

- Users may download and print one copy of any publication from the public portal for the purpose of private study or research.

- You may not further distribute the material or use it for any profit-making activity or commercial gain

- You may freely distribute the URL identifying the publication in the public portal 
Received 00th January 20xx, Accepted 00th January 20xx

DOI: $10.1039 / \times 0 x \times 00000 x$

\section{Lead-free double-halide perovskite $\mathrm{Cs}_{3} \mathrm{BiBr}_{6}$ with well-defined crystal structure and high thermal stability for optoelectronics ${ }^{\dagger}$}

\author{
Yingying Tang, ${ }^{a}$ Mingli Liang, ${ }^{a}$ Bingdong Chang, ${ }^{b}$ Hongyu Sun, ${ }^{c}$ Kaibo Zheng, ${ }^{\text {a,d }}$ Tönu Pullerits, ${ }^{d}$ Qijin \\ $\mathrm{Chi}^{\mathrm{a}}$
}

\begin{abstract}
Halide perovskites have continued to rise as attractive light absorber materials, mainly driven by their potential wide applications in the fields of solar cells, photodetectors, lasers and others. However, the Pb-containing perovskites are posing with serious potential damages to our environment. Thus, there is a strong desire to develop lead-free perovskites as environemtally friendly alternatives. Here, we have shown a successful synthesis of a non-toxic single crystalline perovskite, $\mathrm{Cs}_{3} \mathrm{BiBr}_{6}$, and analyzed its structural characteristics for the first time. This perovskite represents a new structure in terms of double-halide perovskites. The crystal structure is featured by an isolated $\mathrm{BiBr}_{6}$ polyhedra to form a zero-dimensional halide perovskite. The bandgap of this compound is measured to be $2.55 \mathrm{eV}$. High stability against thermal is also clearly shown in $\mathrm{Cs}_{3} \mathrm{BiBr}_{6}$ single crystal. Photodetector based on this compound is fabricated and tested, which exhibits an detectivity of $0.8 * 10^{9}$ Jones and low dark current $(0.03 \mathrm{nA})$ under the $400 \mathrm{~nm}$ light illumination. This has demonstrated its potential for applications in optoelectronic devices. Overall, our results show that $\mathrm{Cs}_{3} \mathrm{BiBr}_{6}$ perovsktie as a lead-free perovskite has interesting structures and promising properties for optoelectronic devices.
\end{abstract}

\section{Introduction}

Halide perovskites have been at the forefront of new-emerging energy materials, due to their great potential in design and fabrication of new-generation optoelectronic devices, such as solar cells, ${ }^{1}$ photodetectors, ${ }^{2-5}$ light-emitting devices, ${ }^{6,7}$ fieldeffect transistors ${ }^{8,9}$ and lasers. ${ }^{10,11}$ Power conversion efficiency (PCE) of $\mathrm{ABX}_{3}(\mathrm{~A}=$ monovalent cation, $\mathrm{B}=$ divalent metal, $\mathrm{X}=$ halides)-based solar cells has largely increased from $3.8 \%$ to $22.6 \%$, which aims towards $30 \%$ in the future. ${ }^{12-16}$ Although they possess unique photo-physical properties such as tunable wavelength, high photoluminescence quantum yield(PLQY), large carrier diffusion length and long carrier lifetime etc on., the current most efficient materials are $\mathrm{Pb}$-containing perovskites. $\mathrm{Pb}$ is detrimental to the environment and human body, however, which might cause memory problems and intellectual disability. Therefore, there is a strong desire to replace toxic $\mathrm{Pb}$ by a benign element such as $\mathrm{Sn}, \mathrm{Ge}$, and $\mathrm{Bi}$ etc. without drastically reducing the conversion efficiency. However, due to the high-energy-lying of 5 s orbitals of $\mathrm{Sn}^{2+}$, its

\footnotetext{
a. Department of Chemistry, Technical University of Denmark, DK-2800 Kongens Lyngby, Denmark

b. DTU Danchip, Technical University of Denmark, 2800 Kongens Lyngby, Denmark

c. Department of Micro- and Nanotechnology, Technical University of Denmark, 2800 Kongens Lyngby, Denmark

${ }^{d .}$ Department of Chemical Physics and NanoLund, Lund University, Box 124, 22100, Lund, Sweden

+Electronic Supplementary Information (ESI) available: See DOI: $10.1039 / x 0 x \times 00000 x$
}

oxidation into $\mathrm{Sn}^{4+}$ would undoubtedly leads to performance reduction drastically. ${ }^{17-19}$ As to Ge-based perovskites, the poor

performance makes them lag far behind the other two alternatives. $^{20-22}$

Among the various alternatives, Bi-based halide perovskites have displayed rapid development. The recently emerged double perovskites, $A_{2} B B^{\prime} X_{6}$, in which $B$ is a monovalent metal and $B^{\prime}$ is a trivalent metal, have demonstrated to be stable and environmentally friendly. Visible to near-infrared absorption of $\mathrm{Cs}_{2} \mathrm{Snl}_{6}$ nanocrystals exhibited high mobility after being fabricated into field-effect transistors. ${ }^{23}$ Solar cells based on $\mathrm{Cs}_{2} \mathrm{AgBiBr}_{6}$ thin films shows a PEC of $2.5 \%$, which represents the highest efficiency among non-lead perovskites. ${ }^{24}$ Especially to the double perovskite single crystal, a detectable dose rate in $\mathrm{Cs}_{2} \mathrm{AgBiBr}_{6}$ single crystal, $59.7 \mathrm{nGy}_{\text {air }} \mathrm{S}^{-1}$, was reported to be as low as $\mathrm{CH}_{3} \mathrm{NH}_{3} \mathrm{PbBr}_{3}$ arisen from the suppressed ion migration. ${ }^{25}$

Except for $A_{2} B^{\prime} X_{6}$, the development of the series of $A_{3} B_{2} X_{9}$ materials are on par with them. Blue $\left(\mathrm{CH}_{3} \mathrm{NH}_{3}\right)_{3} \mathrm{Bi}_{2} \mathrm{Br}_{9}$ quantum dots with a high PLQY of $12 \%$ were successfully synthesized. ${ }^{26}$ For the all-inorganic counterparts, a PLQY of $19.4 \%$ was realized in $\mathrm{CS}_{3} \mathrm{Bi}_{2} \mathrm{Br}_{9}$, exhibiting quite good photostability and moisture stability as well. ${ }^{27}$ In contrast to the fast development in the optical, electronic and optoelectronic properties of $\mathrm{Bi}$ based perovskites, study on their structures is still in its infancy. For the isostructural compounds, the research mainly relies on the powder X-ray diffraction (XRD) data with comparison to the known phase to refine the atomic 
parameters, where large quantities of simulation and calculation are required. This undoubtedly will give rise to the complexity and inconvenience for researchers. For the unkown phase, for example, researchers have chosen to verify the $\mathrm{Cs}_{3} \mathrm{BiBr}_{6}$ phase by excluding the solely known phase of $\mathrm{Cs}_{3} \mathrm{Bi}_{2} \mathrm{Br}_{9}$ in the system of $\mathrm{Cs}-\mathrm{Bi}-\mathrm{Br}$, which is an adventurous and controversial method and needs to be further verified. ${ }^{28}$ This is because there have also other known chemical formula in this system, such as $A_{3} X_{10},{ }^{29} A B X_{5},{ }^{30} A B_{2} X_{7} \cdot{ }^{31}$ This might also lead to the loss of the desired materials due to the mismatch with the current database.

In this work, we demonstrate the synthesis and structural analysis of the single crystal of $\mathrm{Cs}_{3} \mathrm{BiBr}_{6}$ for the first time, which crystallizes in the form of the isolated $\mathrm{BiBr}_{6}$ octahedra within a three-dimensional (3D) framework. Photodetector based on this perovskite was fabricated, displaying high detectivity of around $0.8 * 10^{9}$ Jones under ambient conditions. This material has thus successfully substituted $\mathrm{Pb}^{2+}$ by $\mathrm{Bi}^{3+}$ in the perovskites and could push the toxic issue forward a positive direction. Moreover, it enriches the structural family of non-lead perovskites as well as holds the potential for optoelectronic applications.

\section{Experimental Section}

\section{Chemicals}

All chemical reagents were at least of analytical grade and used as received without further purification. Bismuth bromide $\left(\mathrm{BiBr}_{3}, 99 \%\right)$, Cesium bromide ( $\left.\mathrm{CsBr}, 99.9 \%\right)$, Hydrobromic acid $(\mathrm{HBr}, 48 \%), \mathrm{N}, \mathrm{N}$-Dimethylformamide (DMF, 99.8\%) were all purchased from Sigma-Aldrich.

\section{Synthesis and Crystal Growth of $\mathrm{Cs}_{3} \mathrm{BiBr}_{6}$}

In a typical batch synthesis, $\mathrm{BiBr}_{3}(0.0894 \mathrm{~g}, 0.2 \mathrm{mmol}), \mathrm{CsBr}$ $(0.1038 \mathrm{~g}, 0.49 \mathrm{mmol})$ and $\mathrm{HBr}(2.5 \mathrm{~mL})$ were mixed in a beaker, which was then transferred into an oven at $110{ }^{\circ} \mathrm{C}$ for 2 h. Finally, light yellow crystals were obtained. During the synthesis of the single crystal, if the amount of $\mathrm{CsBr}$ was much lower than the $\mathrm{BiBr}_{3}, \mathrm{Cs}_{3} \mathrm{Bi}_{2} \mathrm{Br}_{9}$ was obtained. Therefore, controlling the ratio between the two raw materials is a key factor to obtain the single crystals of $\mathrm{Cs}_{3} \mathrm{BiBr}_{6}$.

\section{X-ray Crystallographic Studies}

The small crystals of $\mathrm{Cs}_{3} \mathrm{BiBr}_{6}(\sim 0.1 \mathrm{~mm} \times 0.1 \mathrm{~mm} \times 0.05 \mathrm{~mm})$ were selected and mounted on glassy fibers for single-crystal XRD measurements. Data collections were performed on a Bruker APEX-II CCD diffractometer equipped with graphite monochromated Mo K $\alpha$ radiation $(\lambda=0.71073 \AA$ ) at $293 \mathrm{~K}$. The data sets were corrected for Lorentz and polarization factors as well as for absorption by a multi-scan method. ${ }^{32}$ The structure was solved by direct methods and refined by fullmatrix least-squares fitting on $\mathrm{F}^{2}$ by SHELX-97. ${ }^{33}$ All non- $\mathrm{H}$ atoms were refined with anisotropic thermal parameters. The final refined structural parameters were checked by the PLATON program. ${ }^{34}$ Crystallographic data and structural refinements are summarized in Table S1 in Electronic Supplementary Information (ESI). The final refined atomic positions and structural parameters are further provided in ESI (Tables S2-S4). Rietveld refinement of the powder XRD was performed by the Fullprof program.

\section{Material characterization}

X-ray photodetection spectroscopy (XPS) (Thermo Scientific) was performed to analyze the compositions of samples, with Al-K $\alpha$ $(1486 \mathrm{eV})$ as the excitation X-ray source. The pressure of the analysis chamber was maintained at $2 \times 10^{-10} \mathrm{mbar}$ during measurements. All characterizations were carried out at room temperature. Scanning electron Microscope (SEM) and Energy dispersive X-ray spectroscopy (EDX) characterizations were carried out on an FEl Quanta FEG 200 ESEM. The absorption behaviours of the samples were studied by the UV-vis spectrometer from Agilent Technologies (Santa Clara, USA). Absorption $(\alpha / S)$ data was converted from diffuse reflectance spectra using the Kubelka-Munk function, $\alpha / S=(1-R)^{2} / 2 R$, where $R$ is the reflectance coefficient and $\alpha, S$ are the absorption and scattering coefficient. ${ }^{35}$ All the photoelectrochemical characterizations were performed on the Autolab workstation. The phases and purities of all samples were also characterized by powder XRD with $\mathrm{Cu} K \alpha 1(\lambda=1.5406 \AA$ ) radiation. Thermogravimetric analysis (TGA) was performed in the Mettler Toledo, Star ${ }^{\mathrm{E}}$ System (Columbus, OH, USA) with a GC 100 gas controller in a nitrogen atmosphere at a heating rate of 10 ${ }^{\circ} \mathrm{C} / \mathrm{min}$. It should be noted that all the measurements were performed.

\section{Fabrication of Photodetectors}

Prototype optoelectronic devices were prepared in-house. ITO electrodes were prepared by the ultrasonic cleaning in acetone, ethanol, and Milli-Q water successfully. $\mathrm{Cs}_{3} \mathrm{BiBr}_{6}$ single crystals were dissolved into DMF and then a certain amount of solution was deposited on the device surface by drop-casting, followed by annealing at $100{ }^{\circ} \mathrm{C}$. The working area was $0.004 \mathrm{~cm}^{2}$.
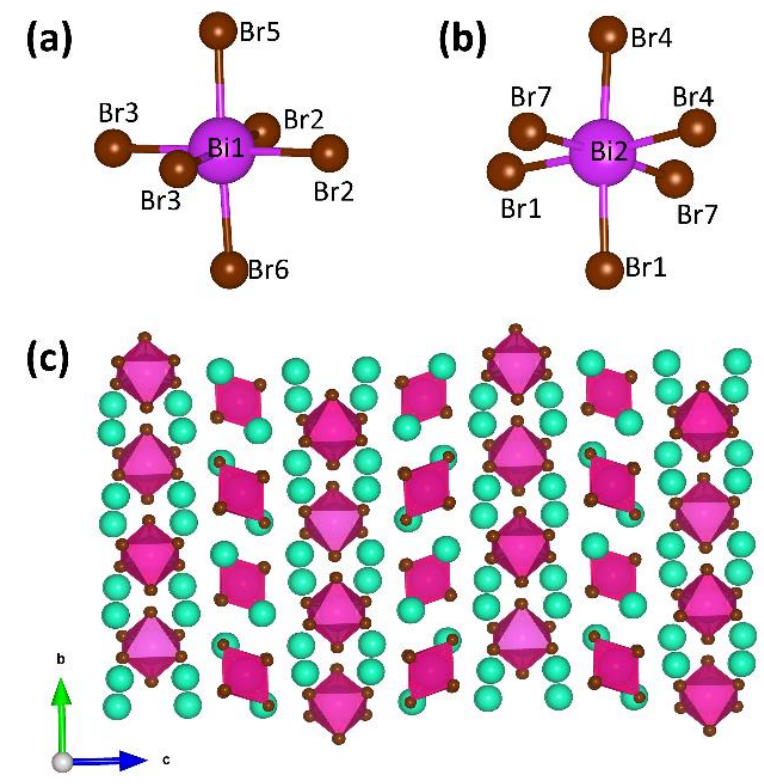
Fig. 1 View of structural characteristics for $\mathrm{Cs}_{3} \mathrm{BiBr}_{6}$. Bromidecoordination environment for (a) Bi1 and (b) Bi2. (c) $3 \mathrm{D}$ framework on the $b c$ plane. Color codes: $\mathrm{Cs}$, green; $\mathrm{Bi}$, purple; $\mathrm{Br}$, brown.

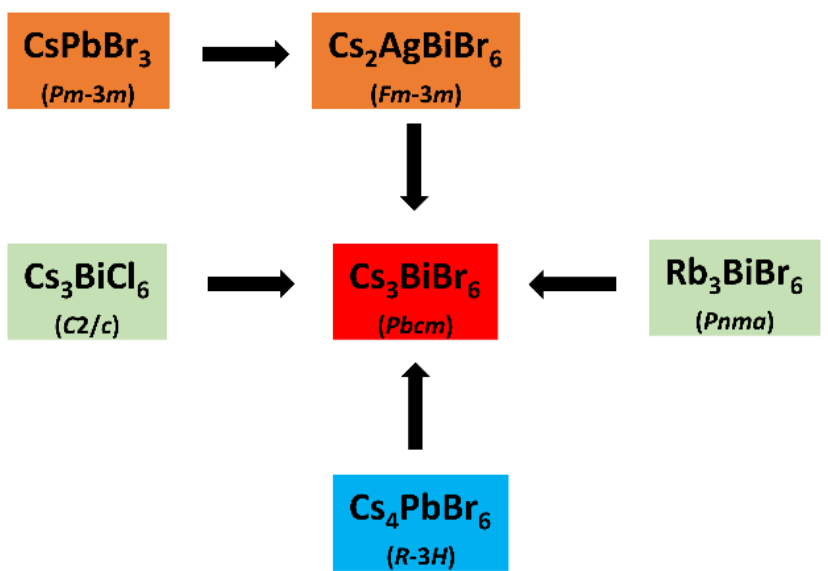

Fig. 2 Chemical and structural relationship among a series of perovskites.

\section{Results and discussion}

$\mathrm{X}$-ray analysis indicates clearly that the compound of $\mathrm{Cs}_{3} \mathrm{BiBr}_{6}$ crystallizes in the orthorhombic system of space group $\mathrm{Pbcm}$ with $a=8.689(2) \AA, b=13.628(1) \AA, c=27.694(9) \AA$ (Table S1). There are two $\mathrm{Bi}$ atoms, three $\mathrm{Cs}$ atoms, and seven $\mathrm{Br}$ atoms in an asymmetric unit. Two independent $\mathrm{Bi}$ atoms are located at their Wyckoff position of $4 c$ and $4 d$, respectively. As shown in Fig. $1 \mathrm{a}$ and $1 \mathrm{~b}$, each $\mathrm{Bi}$ atom is coordinated by six $\mathrm{Br}$ atoms, forming $\mathrm{BiBr}_{6}$ octahedra. All of the $\mathrm{BiBr}_{6}$ octahedra are distorted, as illustrated in the bond lengths and angles in Table S3. The 3D framework of $\mathrm{Cs}_{3} \mathrm{BiBr}_{6}$ is displayed in Fig. 1c, where all $\mathrm{BiBr}_{6}$ octahedra are isolated from each other forming $\mathrm{OD}$ perovskite structure. $\mathrm{Cs}^{+}$cations filled up the spaces left by the unconnected $\mathrm{BiBr}_{6}$ octahedra. In particular, $\mathrm{Bi} 1$ locates at the mirror plane while $\mathrm{Bi} 1$ and $\mathrm{Cs} 3$ form a pseudo-triangular tunnel, which are filled up by Cs2 atoms (Fig. S1a). In contrast, $\mathrm{Bi} 1, \mathrm{Bi} 2$ and $\mathrm{Cs} 3$ form a square tunnel, where Cs1 atoms are located forming a traditional $\mathrm{ABX}_{3}$ structure. In order to better understand the structural characteristics of this compound, a relationship among $\mathrm{Cs}_{3} \mathrm{BiBr}_{6}, \mathrm{CsPbBr}_{3}{ }^{36} \mathrm{Cs}_{2} \mathrm{AgBiBr}_{6}$ and $\mathrm{Cs}_{4} \mathrm{PbBr}_{6}{ }^{37}$ are discussed, as displayed in Fig. 2. It is known that if one $\mathrm{Pb}$ atom is substituted by $\mathrm{Ag}$ and the neighbored one is substituted by $\mathrm{Bi}$ in $\mathrm{CsPbBr}_{3}$, the perovskite $\mathrm{Cs}_{2} \mathrm{AgBiBr}_{6}$ forms, where all $\mathrm{BiBr}_{6}$ are separated by $\mathrm{Cs}^{+}$and $\mathrm{Ag}^{+}$. This comparison has been generally used to illustrate the relationship between $\mathrm{CsPbBr}_{3}$ and $\mathrm{Cs}_{2} \mathrm{AgBiBr}_{6}$. Despite this, there is a clear statement for the relationship between $\mathrm{Cs}_{3} \mathrm{BiBr}_{6}$ and $\mathrm{Cs}_{2} \mathrm{AgBiBr}_{6}$, where $\mathrm{Ag}$ in $\mathrm{Cs}_{2} \mathrm{AgBiBr}_{6}$ is substituted by $\mathrm{Cs} 3$ atom in $\mathrm{Cs}_{3} \mathrm{BiBr}_{6}$. At the same time, the difference comes, which is that after the incorporation of $\mathrm{Cs} 3$, the crystallographic symmetry of $\mathrm{Cs}_{3} \mathrm{BiBr}_{6}$ is lower than that in $\mathrm{Cs}_{2} \mathrm{AgBiBr}_{6}$, leading to a distinct structural characteristics in $\mathrm{Cs}_{3} \mathrm{BiBr}_{6}$. Meanwhile, we could also clearly observe the similarity of $\mathrm{Cs}_{3} \mathrm{BiBr}_{6}$ with that of $\mathrm{Cs}_{4} \mathrm{PbBr}_{6}$, where one monovalent $\mathrm{Cs}^{+}$and one divalent $\mathrm{Pb}^{2+}$ are simultaneously substituted by a trivalent $\mathrm{Bi}$ atom. Both structures are a characteristic of isolated $\mathrm{MX}_{6}$ octahedra, although crystallized in different crystal system. Even compared to its
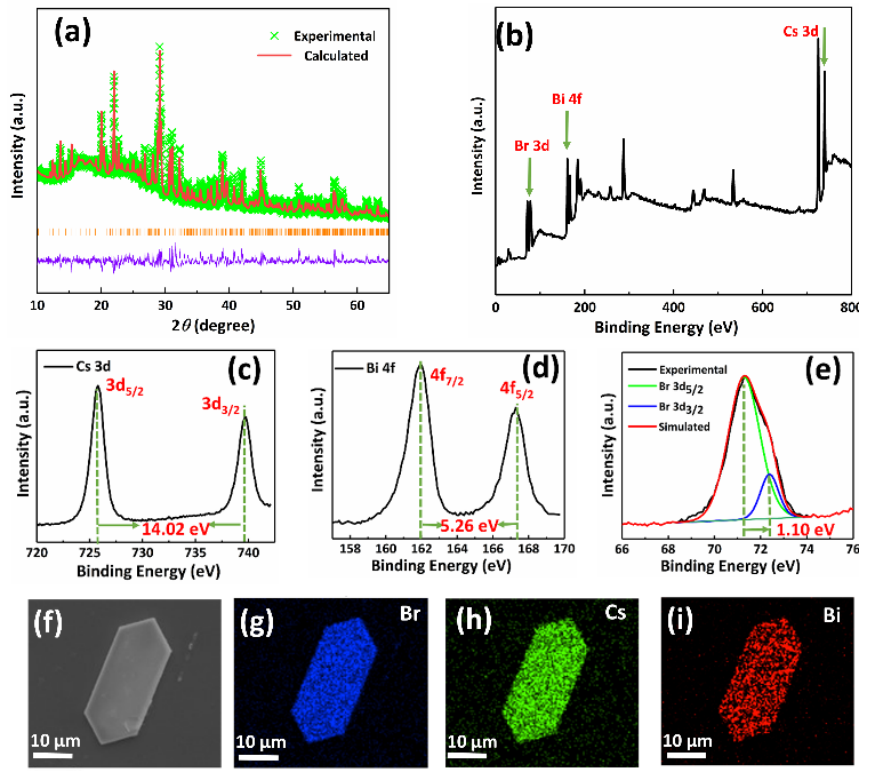

Fig. 3 (a) Rietvield refinement of the experimental powder XRD pattern of $\mathrm{Cs}_{3} \mathrm{BiBr}_{6}$ and calculated XRD patterns from single crystal. XPS spectra: (b) survey spectrum; (c) Cs 3d; (d) Bi 4f; (e) $\mathrm{Br} 3 \mathrm{~d}$. (f) Electron micrograph of the microstructure for single crystal $\mathrm{Cs}_{3} \mathrm{BiBr}_{6}$. (g-i) EDX mapping of the element distribution: (g) $\mathrm{Br}$, (h) $\mathrm{Cs}$, (i) Bi.

isomers of $\mathrm{Cs}_{3} \mathrm{BiCl}_{6}$ and $\mathrm{Rb}_{3} \mathrm{BiBr}_{6}$ (Table S5), ${ }^{38-40}$ different crystallographic systems and structures are exhibited. It further reminds us that much more attention is needed for the phase check of a new material if using the known phase as a reference (Fig. S2).

The purity of samples was confirmed by powder X-ray diffraction (Fig. 3a). The dominant diffraction peaks of $2 \theta=$ $13.66^{\circ}, 20.09^{\circ}, 22.06^{\circ}, 29.19^{\circ}, 30.08^{\circ}, 32.22^{\circ}, 39.08^{\circ}, 44.98^{\circ}$, $56.43^{\circ}$, could be identified to be the crystal planes of (112),

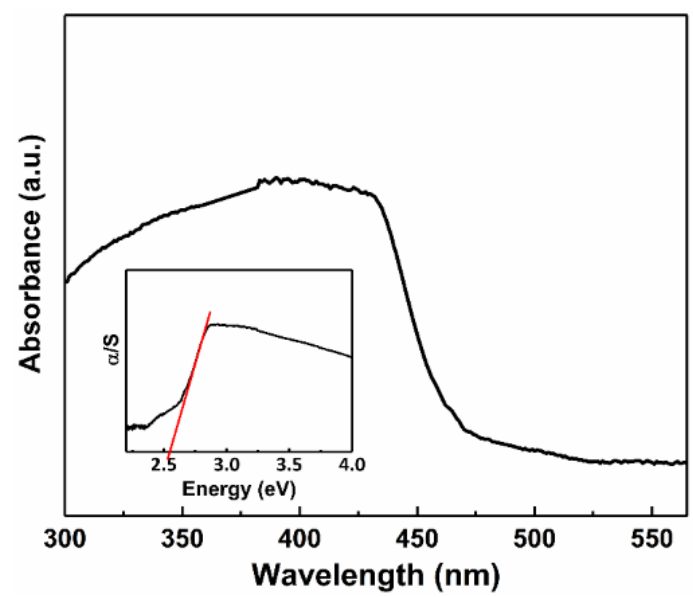


Fig. 4 Absorption spectrum of $\mathrm{Cs}_{3} \mathrm{BiBr}_{6}$. Inset: the Tauc plot showing the bandgap of ca. 2.55 eV.
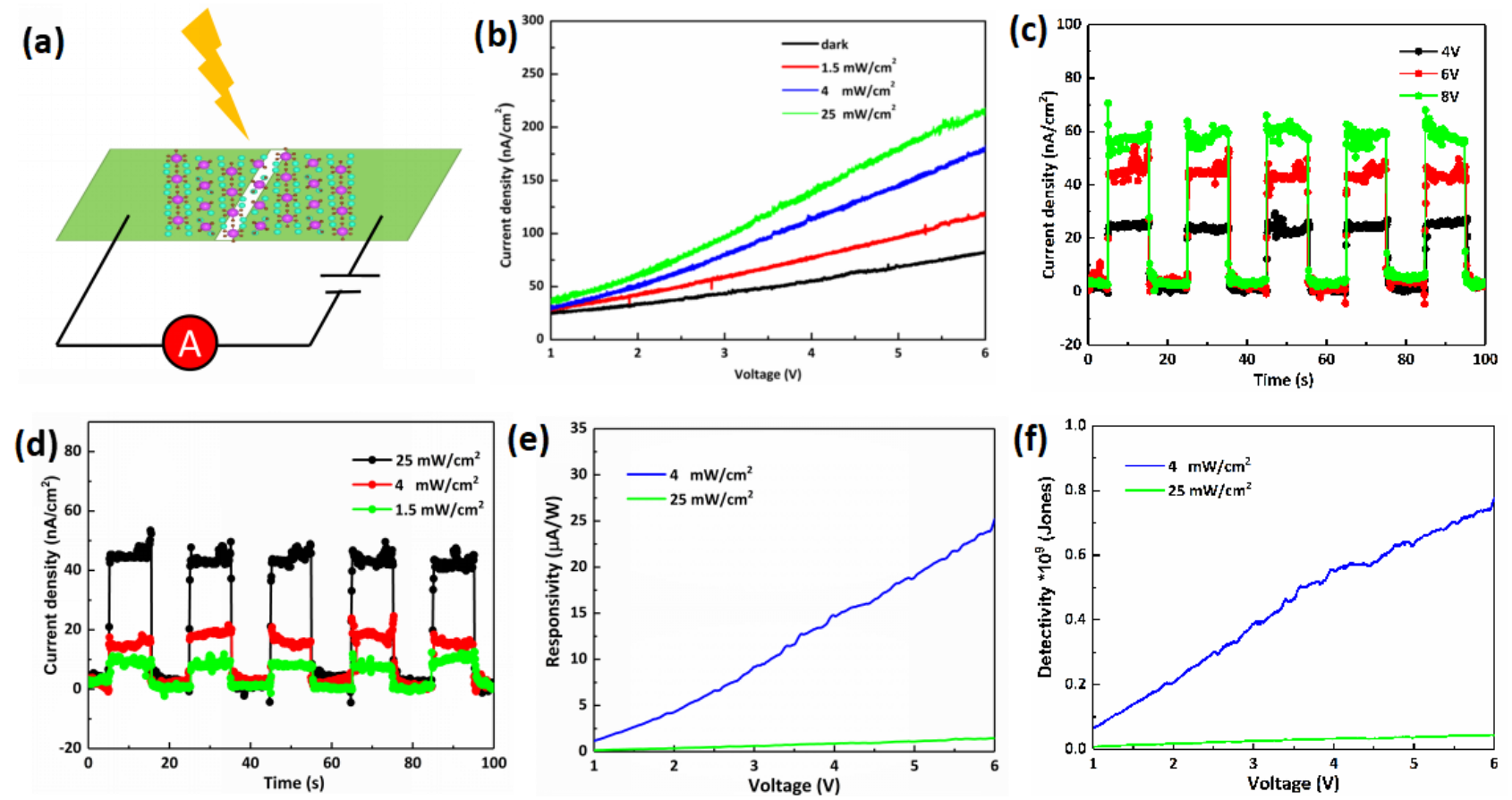

Fig. 5 (a) Schematic view of the photodetector based on $\mathrm{Cs}_{3} \mathrm{BiBr}_{6}$. Periodic photoresponse behavior of $\mathrm{Cs}_{3} \mathrm{BiBr}_{6}$ under power density of $400 \mathrm{~nm}$ wavelength. (b) Photocurrent under various voltages with light density of $25 \mathrm{~mW} / \mathrm{cm}^{2}$. (c) Photocurrent under various of light intensity and bias of 6 V. (d) I-V characteristics under different power density. (e) Responsivity. (f) Detectivity.

(115), (130), (044) (233), (312), (334), (329) and (367), respectively. Furthermore, we used the Fullprof software to check the purity in detail. The Rietveld refinement results show the good agreement between observed (cross) and fitted (solid lines) diffraction patterns with the resulting $\chi^{2}$ of 4.40 . This consistence between the experimental and simulated XRD patterns confirms the phase purity of the resulting material. Meanwhile, we further confirmed the valence state and element distribution by the XPS measurements (Fig. 3b-3e). From the XPS results, we could observe the signals of Cs $\left(3 d_{5 / 2}\right.$, $3 d_{3 / 2}$, separated spin-orbitals components $\left.\Delta=14.02 \mathrm{eV}\right), \mathrm{Bi}$ $\left(4 f_{7 / 2}, 4 f_{5 / 2}, \Delta=5.26 \mathrm{eV}\right)$ and $\mathrm{Br}\left(3 d_{5 / 2}, 3 d_{3 / 2}, \Delta=1.10 \mathrm{eV}\right)$, which indicates their valence $(+1,+3,-1$, respectively) to be consistent with the formula and confirms the existence of all elements in this material (Fig. 3c, 2d, 2e). Besides, the morphology of the as-synthesized single crystal was measured by SEM, where a smooth surface was observed on the single crystal (Fig. 3f). Elemental composition was mapped by Energy dispersive $\mathrm{X}$-ray (EDX) to study the elemental distribution, Fig. 3g-3i. All elements of $\mathrm{Cs}, \mathrm{Bi}$, and $\mathrm{Br}$ were observed and distributed uniformly on the surface of the single crystal.

To analyze the optical properties of $\mathrm{Cs}_{3} \mathrm{BiBr}_{6}$, the UV-vis absorption spectrum was measured. $\mathrm{Cs}_{3} \mathrm{BiBr}_{6}$ displays an absorption edge at about $485 \mathrm{~nm}$, and the bandgap of the compound is calculated to be $2.55 \mathrm{eV}$ according to the Tauc plot (the inset of Fig. 4). As to the thermal stability, the samples of $\mathrm{Cs}_{3} \mathrm{BiBr}_{6}$ single crystals are heated under a nitrogen atmosphere, as shown in the TGA curve in Fig. S3. It can be observed that $\mathrm{Cs}_{3} \mathrm{BiBr}_{6}$ is stable with increasing temperature up to $425^{\circ} \mathrm{C}$, while the onset of weight loss is observed. ${ }^{41,42}$ As a comparison, the $\mathrm{CH}_{3} \mathrm{NH}_{3} \mathrm{PbBr}_{3}$ was also investigated. For $\mathrm{CH}_{3} \mathrm{NH}_{3} \mathrm{PbBr}_{3}$, the loss in the weight of the sample starts from $285^{\circ} \mathrm{C}$, while a plateau is seen in the temperature range of $420-455^{\circ} \mathrm{C}$. This step was attributed to the loss of $\mathrm{CH}_{3} \mathrm{NH}_{3} \mathrm{Br}$. Furthermore, a rapid drop in the weight loss curve is clearly seen above $455^{\circ} \mathrm{C}$, indicating further decomposition of the system. This indicates a higher thermal stability of $\mathrm{Cs}_{3} \mathrm{BiBr}_{6}$ than in the $\mathrm{CH}_{3} \mathrm{NH}_{3} \mathrm{PbBr}_{3}$.

In order to check the optoelectronic property of the $\mathrm{Cs}_{3} \mathrm{BiBr}_{6}$, a photodetector was fabricated on ITO electrodes as illustrated in Fig. 5a. The morphology of the film was examined as displayed in Fig. S4. Fig. $5 b$ shows the $\mathrm{I}-\mathrm{V}$ characteristics under dark and light illumination at different power density. Obviously, the photocurrent increases with the increase of the light density and voltage. Under $6 \mathrm{~V}$ bias, ultralow dark current of $0.03 \mathrm{nA}$ was obtained. Fig. $5 \mathrm{c}$ shows the dynamic currenttime (i-t) curves for the $\mathrm{Cs}_{3} \mathrm{BiBr}_{6}$ based photodetectors under repeating switching of $400 \mathrm{~nm}$ monochromatic illumination with a light density of $25 \mathrm{~mW} / \mathrm{cm}^{2}$. The amperometric i-t curves demonstrate that the device can repeatedly produce stable photocurrent signals in response to periodical light ON and OFF. Upon illumination, the photocurrent increases to 70 $\mathrm{nA} / \mathrm{cm}^{2}$ by increasing the voltage up to $8 \mathrm{~V}$. Besides, the photoresponse of the detector versus light power density was 
also measured, as shown in Fig. $5 \mathrm{~d}$. With the increase of the power density, the photocurrent also increases, reaching to 50 $\mathrm{nA} / \mathrm{cm}^{2}$ under the light density of $25 \mathrm{~mW} / \mathrm{cm}^{2}$ at the voltage of $6 \mathrm{~V}$. The above results from i-t curves are consistent with our conslusions from the I-V curves. Hereafter, we focus on the investigation of responsivity and detectivity of the photodetector. Fig. $5 \mathrm{e}$ and $5 \mathrm{f}$ show the responsivity and detectivity of the photodetector versus voltage and light density, respectively. The responsivity $(R)$ which can be understood as electrical output per optical input, is calculated by the following equation: ${ }^{43}$

$R=\left(I_{P C}-I_{\text {dark }}\right) /\left(P_{\text {irra }} \cdot S\right)$

where $I_{P C}$ and $I_{\text {dark }}$ are currents measured with and without illumination, respectively. $P_{\text {irra }}$ is the irradiation power density and $S$ is the effective working area of the detector. Detectivity $\left(D^{*}\right)$ as a figure merit of evaluating the ability to detect weak light can be calculated using equation (2).

$$
D^{*}=R /\left(2 e^{*} I_{\text {dark }}\right)^{1 / 2}
$$

At the voltage of $6 \mathrm{~V}$, the responsivity of this material can reach 25 $\mu \mathrm{A} / \mathrm{W}$ at a light density of $4 \mathrm{~mW} / \mathrm{cm}^{2}$. And their detectivity is calculated to be of around $0.8 * 10^{9}$ Jones. External quantum efficiency (EQE) is calculated to be $0.008 \%$ under voltage of $6 \mathrm{~V}$ and power density of $4 \mathrm{~mW} / \mathrm{cm}^{2}$ according to the equation of $E Q E=$ $R \cdot h c /(e \lambda)$ (Fig. S5). After exposing to $400 \mathrm{~nm}$ light illumination, the rise and decay time of the device was extracted to be $50 \mathrm{~ms}$ and 60 ms, respectively (Fig. S6). Meanwhile, we also checked the photodetection ability of this material toward white light, as shown in Fig. S7. It is clear that the device behaves similarly with that in $400 \mathrm{~nm}$ light, despite a weak responsivity was observed. At a $6 \mathrm{~V}$ bias, the responsivity towards white light was only $0.2 \mu \mathrm{A} / \mathrm{W}$, much lower than that in $400 \mathrm{~nm}$ wavelength light.

\section{Conclusions}

In summary, we have successfully synthesized a non-toxic single crystal of perovskite, $\mathrm{Cs}_{3} \mathrm{BiBr}_{6}$. And it is the first time to analyse its crystallography structure, which features as an isolated $\mathrm{BiBr}_{6}$ polyhedra. Photodetector based on this perovskite is fabricated, exhibiting a good detectivity of $0.8 * 10^{9}$ Jones under the $400 \mathrm{~nm}$ light illumination, demonstrating the potential for application into optoelectronic devices. Besides, this material displays high stability against thermal and moisture. Finally, this work affords an example of the utilization of non-toxic perovskites for the photodetection. It further facilitates the development of lead-free perovskites toward environment friendly energy conversion devices.

\section{Conflicts of interest}

There are no conflicts to declare.

\section{Acknowledgements}

This work was supported by the Villum Foundation, Independent Research Fund Denmark-Nature Sciences (DFF-FNU,
Project No DFF-7014-00302), Independent Research Fund Denmark-Sapere Aude starting grant (No. 7026-00037A) and Swedish Research Council VR starting grant (No. 2017-05337). We thank Christian Engelbrekt for the help in using optical sources.

\section{Notes and references}

1 N. Arora, M. Ibrahim Dar, A. Hinderhofer, N. Pellet, F. Schreiber, S. Mohammed Zakeeruddin and M. Grätzel, Science, 2017, 358, 768-771.

2 H. R. Xia, J. Li, W. T. Sun and L. M. Peng, Chem. Commun., 2014, 50, 13695.

3 R. Dong, Y. J. Fang, J. Chae, J. Dai, Z. G. Xiao, Q. F. Dong, Y. B. Yuan, A. Centrone, X. C. Zeng and J. S. Huang, Adv. Mater., 2015, 27, 1912-1918.

4 Z. J. Tan, Y. Wu, H. Hong, J. B. Yin, J. C. Zhang, L. Lin, M. Z. Wang, X. Sun, L. Z. Sun, Y. C. Huang, K. H. Liu, Z. F. Liu and H. L. Peng, J. Am. Chem. Soc., 2016, 138, 16612-16615.

5 M. I. Saidaminov, V. Adinolfi, R. Comin, A. L. Abdelhady, W. Peng, I. Dursun, M. Yuan, S. Hoogland, E. H. Sargent and O. M. Bakr, Nat. Commun., 2015, 6, 8724.

6 P. Schulz, E. Edri, S. Kirmayer, G. Hodes, D. Cahen and A. Kahn, Energy Environ. Sci., 2014, 7, 1377-1381.

7 G. R. Li, Z. -K. Tan, D. W. Di, M. L. Lai, L. Jiang, J. H. -W. Lim, R. H. Friend and N. C. Greenham, Nano Lett., 2015, 15, 2640-2644.

8 X. Y. Chin, D. Cortecchia, J. Yin, A. Bruno and C. Soci, Nat. Commun., 2015, 6, 7383.

9 S. P. Senanayak, B. Y. Yang, T. H. Thomas, N. Giesbrecht, W. C. Huang, E. Gann, B. Nair, K. Goedel, S. Guha, X. Moya, C. R. McNeill, P. Docampo, A. Sadhanala, R. H. Friend and H. Sirringhaus, Sci. Adv., 2017, 3, e1601935.

10 S. D. Stranks, S. M. Wood, K. Wojciechowski, F. Deschler, M. Saliba, H. Khandelwal, J. B. Patel, S. J. Elston, L. M. Herz, M. B. Johnston, A. P. H. J. Schenning, M. G. Debije, M. K. Riede, S. M. Morris, H. J. Snaith, Nano Lett., 2015, 15, 4935-4941.

11 G. C. Xing, N. Mathews, S. S. Lim, N. Yantara, X. F. Liu, D. Sabba, M. Grätzel, S. Mhaisalkar and T. C. Sum, Nat. Mater., 2014, 13, 476-480.

12 A. Kojima, K. Teshima, Y. Shirai and T. Miyasaka, J. Am. Chem. Soc., 2009, 131, 6050-6051.

13 M. M. Lee, J. Teuscher, T. Miyasaka, T. N. Murakami and H. J. Snaith, Science, 2012, 338, 643-647.

14 M. Liu, M. B. Johnston and H. J. Snaith, Nature, 2013, 501, 395-398.

15 N. J. Jeon, J. H. Noh, W. S. Yang, Y. C. Kim, S. Ryu, J. Seo and S. I. Seok, Nature, 2015, 517, 476-480.

16 N. J. Jeon, H. Na, E. H. Jung, T. -Y. Yang, Y. G. Lee, G. Kim, H. -W. Shin, S. II Seok, J. Lee, J. Seo, Nature Energy, 2018, DOI: https://doi.org/10.1038/s41560-018-0200-6.

17 T. Leijtens, R. Prasanna, A. Gold-Parker, M. F. Toney, and M. D. McGehee, ACS Energy Lett., 2017, 2, 2159-2165.

18 T. -B. Song, T. Yokoyama, S. Aramaki, and M. G. Kanatzidis, ACS Energy Lett., 2017, 4, 897-903.

19 E. J. Yeom, S. S. Shin, W. S. Yang, S. J. Lee, W. P. Yin, D. Kim, J. H. Noh, T. K. Ahn and S. II Seok, J. Mater. Chem. A, 2017, 5, 79-86.

20 C. C. Stoumpos, L. Frazer, D. J. Clark, Y. S. Kim, S. H. Rhim, A. J. Freeman, J. B. Ketterson, J. I. Jang, and M. G. Kanatzidis, J. Am. Chem. Soc., 137, 21, 6804-6819.

21 I. Kopacic, B. Friesenbichler, S. F. Hoefler, B. Kunert, H.Plank, T. Rath, and G. Trimmel, ACS Appl. Energy Mater., 2018, 1, 343-347. 
22 T. Krishnamoorthy, H. Ding, C. Yan, W. L. Leong, T. Baikie, Z. Y. Zhang, M. Sherburne, S. Z. Li, M.Asta, N. Mathews and S. G. Mhaisalkar, J. Mater. Chem. A, 2015, 3, 2382923832.

23 L. -Z. Lei, Z. -F. Shi, Y. Li, Z. -Z. Ma, F. Zhang, T. -T.Xu, Y. -T. Tian, D. Wu, X. -J. Lia and G. -T. Du, J. Mater. Chem. C, 2018, 10.1039/C8TC02305K.

24 A. F. Wang, X. X. Yan, M. Zhang, S. B. Sun, M. Yang, W. Shen, X. Q.Pan, P. Wang and Z. T. Deng, Chem. Mater., 2016, 28, 8132-8140

25 W. C. Pan, H. D. Wu, J. J. Luo, Z. Z. Deng, C. Ge, C. Chen, X. W. Jiang, W. -J. Yin, G. D. Niu, L. J. Zhu, L. X. Yin, Y. Zhou, Q. G. Xie, X. X. Ke, M. L. Sui and J. Tang, Nature Photon., 2017, 11, 726-732.

26 M. Leng, Z. Chen, Y. Yang, Z. Li, K. Zeng, K. Li, G. Niu, Y. He, Q. Zhou, J. Tang, Angew Chem. Int. Engl., 2016, 55, 1501215016.

27 M. Y. Leng, Y.Yang, K. Zeng, Z. W. Chen, Z. F. Tan, S. R. Li, J. H. Li, B. Xu, D. B. Li, M. P. Hautzinger, Y. P. Fu, T. Y. Zhai, L. Xu, G. D. Niu, S. Jin, J. Tang, Adv. Funct, Mater., 2018, 1, 1704446 .

28 S. E. Creutz, E. N. Crites, M. C. De Siena and D. R. Gamelin, Nano Lett., 2018, B, 1118-1123.

29 X. -W. Tong, W. -Y. Kong, Y. -Y. Wang, J. -M. Zhu, L. -B. Luo, Z. -H. Wang, ACS Appl. Mater. Interfacs, 2017, 9, 1897718985.

30 C. Ji, P. Wang, Z. Wu, Z. Sun, L. Li, J. Zhang, W. Hu, M. Hong, J. Luo, Adv. Funct. Mater., 2018, 28, 1705467.

31 J. -H. Chang, A. Wolff, M. Ruck, Z. Anorg. Allg. Chem., 2016, 6, 456-460.

32 CrystalClear, version 1.3.5; Rigaku Corp.: The Woodlands, TX, 1999.

33 G. M. Sheldrick, Crystallographic Software Package, SHELXTL, version 5.1; Bruker AXS: Madison, WI, 1998.

34 A. L. Spek, J. Appl. Crystallogr., 2003, 36, 7.

35 G. Kortüm, Reflectance Spectroscopy; Springer-Verlag: New York, 1969.

36 S. Hirotsu, J. Harada, M. lizumi and K. Gesi, J. Phys. Soc. Jpn., 1974, 37, 1393-1398.

37 M. I. Saidaminov, J. Almutlaq, S. Sarmah, I. Dursun, A. A. Zhumekenov, R. Begum, J. Pan, N. Cho, O. F. Mohammed and O. M. Bakr, ACS Energy Lett., 2016, 1, 840-845.

38 M. Shimizu, M. Koshimizu, Y. Fujimoto, T. Yanagida, S. Ono, K. Asai, Opt. Mater., 2016, 61, 115-118.

39 F. Lazarini, Acta Cryst., 1978, B34, 2288-2290.

40 C. W. M. Timmermans, G. Blasse, Phys. Stat. Sol., 1983, b118, 353.

41 M. Y. Leng, Y. Yang, K. Zeng, Z. W. Chen, Z. F. Tan, S. R. Li, J. H. Li, B. Xu, D. B. Li, M. P. Hautzinger, Y. P. Fu, T. Y. Zhai, L. Xu, G. D. Niu, S. Jin and J. Tang, Adv. Funct. Mater., 2018, 28, 1704446.

42 L. Zhou, Y. -F. Xu, B. -X. Chen, D. -B. Kuang and C.-Y. Su, Small, 2018, 14, 1703762.

43 J. X. Ding, S. J. Du, Z. Y. Zuo, Y. Zhao, H. Z. Cui and X. Y. Zhan, J. Phys. Chem. C, 2017, 121, 4917-4923. 

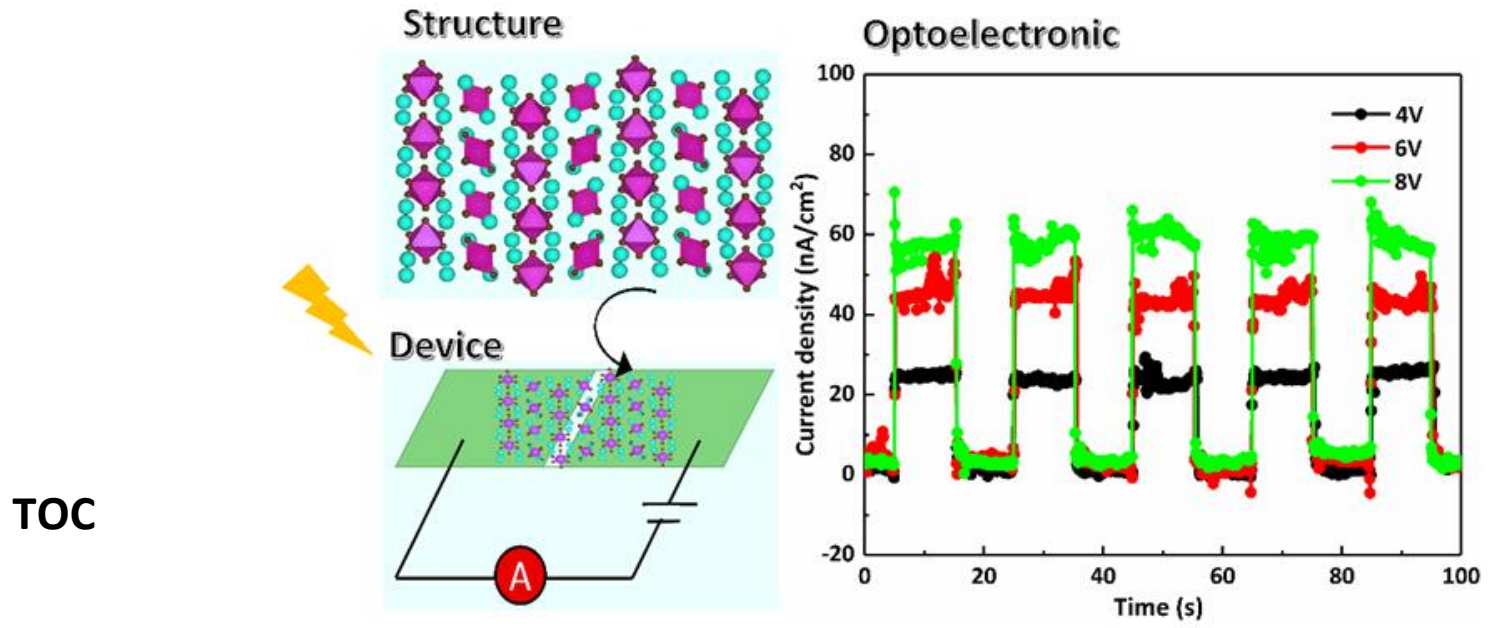

Synopsis: A lead-free double halide perovskite with well-defined structure and high thermal stability was synthesized, providing a new candidate material for fabricating non-toxic optoelectronic devices. 